\title{
Plasma progesterone concentrations in female little brown bats (Myotis lucifugus) during hibernation
}

\author{
G. D. Buchanan and E. V. YoungLai \\ Reproductive Biology Research Program, Faculty of Health Sciences, McMaster University, \\ Hamilton, Ontario, Canada L8N $3 Z 5$
}

\begin{abstract}
Summary. Monthly collections of hibernating little brown bats contained (1) nulliparous females with small uteri and no antral follicles, (2) nulliparous females with swollen uteri and mature follicles, and (3) parous females, which, despite obvious differences in reproductive status, had equivalent plasma progesterone values. During the principal study season, mean monthly progesterone concentrations (measured by radioimmunoassay) showed recurrent increases with an apparent periodicity of about 60 days, but limited data obtained in the subsequent season did not. However, comparison of activity patterns in the two seasons with monthly progesterone concentrations suggests that ovarian activity during hibernation is affected by variations in metabolic level.

We saw no evidence that nulliparous bats with small uteri developed antral follicles during hibernation. Despite their apparent immaturity, however, they had cornified vaginae and most were demonstrably inseminated. These indications of oestrus and the lack of differences between their plasma progesterone concentrations and those of patently mature females suggest that they were physiologically post-pubertal but failed to complete folliculogenesis before entering hibernation.
\end{abstract}

Keywords: progesterone; bat; hibernation

\section{Introduction}

The reproductive cycle of the little brown bat (Myotis lucifugus), and other heterothermic vespertilionid and rhinolophid bats (Wimsatt, 1969; Oxberry, 1979; Racey, 1982), is characterized by interposition of a long hibernation period between mating and ovulation. Hibernating females, have viable spermatozoa in the reproductive tract (Racey et al., 1987) and one glycogen-laden (Wimsatt \& Kallen, 1957) mature follicle destined to ovulate 1-3 days after permanent arousal (Buchanan, 1987). Although Guthrie \& Jeffers (1938) reported recurrent waves of growth in secondary follicles of hibernating bats, the static appearance of the mature follicle (Wimsatt, 1944) and studies showing that anterior pituitary extracts, which will induce ovulation at any time in aroused bats, are ineffective in torpid bats (Wimsatt \& Kallen, 1957; Wimsatt, 1960) led to the conclusion that ovarian activity is arrested during hibernation. However, follicular activity and hormonal activity need not coincide in vespertilionids, since, except during pregnancy steroidogenesis occurs principally in the ovarian interstitial tissue (Myotis grisescens: Guraya \& Greenwald, 1964; Antrozous pallidus: Oxberry, 1979; $M$. lucifugus: unpublished observations).

The original aim of this study was to evaluate ovarian activity in hibernating little brown bats by measuring peripheral ovarian steroid levels. A second aim arose from the presence in the hibernating colony of a number of nulliparous females with small uteri and no mature antral follicles (Buchanan \& YoungLai, 1986; Buchanan, 1987). Although apparently immature, such bats have fully cornified vaginae and most are demonstrably inseminated. It is therefore possible that they are sexually competent and will develop antral follicles during hibernation. Indeed, Wimsatt \& Kallen 
(1957) asserted that some young females lack a mature follicle at the time of mating, but develop one later, although it is not clear whether they meant before or after the onset of hibernation. Accordingly, we undertook to compare circulating steroid concentrations amongst bats of different reproductive categories, on the premise that sexually immature bats would exhibit lower values than patently mature bats, at least at the onset of hibernation. If ovarian activity was depressed during hibernation, steroid concentrations would be expected to fall to basal values as has been reported for the pallid bat (Oxberry, 1979), the only species for which steroid levels during hibernation are known. If nulliparous bats with small uteri developed an antral follicle during hibernation it was expected that there would be some concomitant change in plasma steroids as a result of gonadotrophin stimulation.

\section{Materials and Methods}

Female bats (Myotis lucifugus lucifugus) were collected in Craigmont Mine, southwestern Renfrew County $\left(45^{\circ} 18^{\prime} \mathrm{N}\right)$, Ontario. The mine is a level adit approximately $122 \mathrm{~m}$ long without air vents or shafts. The photic region ends abruptly at a $45^{\circ}$ turn $23-24.4 \mathrm{~m}$ from the entrance, and the microclimate beyond is uniform the entire year (temperature, $6.0-6.5^{\circ} \mathrm{C}$; humidity, $97-100 \%$; no draughts). The formation of an ice dam, and later a solid ice curtain, effectively discourages casual entry during winter and we have seen no evidence of entry by others during hibernation.

Collection and handling. All collections were made along a fixed route in the interior one-third of the mine where females, roosting alone or in small groups, are abundant. The only criterion for specimen selection was sex; however, banded bats or clusters containing banded bats were deliberately avoided. Thus, successive collections are comparable even though there is no assurance that they represent an unbiased sample of the total female population. During 1983 84, collections were made in late September (early hibernation) and mid-monthly thereafter through March. The next season, regular collections were made in September and October. Subsequently, small numbers of bats were collected at irregular intervals. Bats were placed in small refrigerated containers as collected, brought to Hamilton, and placed in an artificial hibernaculum $8-10 \mathrm{~h}$ after collection. Some bats experienced a brief arousal shortly after collection, but there was little activity when they were placed in the artificial hibernaculum, and all were found in deep torpor shortly thereafter. Specimens were examined $24.48 \mathrm{~h}$ after collection.

Autopsy. Bats were weighed, then killed by cervical dislocation. The thorax was opened quickly and blood from the pectoral and subclavian veins was collected in heparinized capillary tubes, which were immediately centrifuged for $10 \mathrm{~min}$ in a Clay-Adams micro-haematocrit centrifuge. Capillary tubes were fractured at the cell-plasma interface, and the plasma portion was sealed with wax and frozen at $-20^{\circ} \mathrm{C}$ until assayed. Reproductive tracts were examined in situ, excised, photographed, and processed for further analysis.

Histology and histochemistry. Representative tracts were fixed in Serra's (Serra \& Queiroz Lopes, 1945) or cold Rossman's (Rossman, 1940) fixatives, dehydrated in ethanol and $n$-butanol (Morse, 1945) and embedded in paraplast. Frontal sections 5-7 $\mu \mathrm{m}$ thick were prepared and stained in Masson's trichrome (Lillie, 1965) for general histology or periodic acid-Schiff (PAS) reagent and Alcian Blue (Pearse, 1968), with and without prior diastase extraction, to demonstrate glycogen and mucopolysaccharides.

Steroid assay. The radioimmunoassay procedure used to measure plasma progesterone (Buchanan \& YoungLai, 1986) uses antibodies produced in rabbits against progesterone-1 1 - $\alpha$-hemisuccinyl-bovine serum albumin and $\left[1,2-{ }^{3} \mathrm{H}\right]$ progesterone as the labelled ligand. At a dilution of $1: 10000$, this antibody has less than $0 \cdot 1 \%$ cross-reactivity with $20 \alpha$-dihydroprogesterone, dihydrotestosterone, testosterone, androstenedione, oestrone, and oestradiol. Crossreactivity with corticosterone is $1.2 \%$. The sensitivity limit of the assay is $10 \mathrm{pg} /$ tube. Protein in plasma samples $(10-41 \mu \mathrm{l})$ was precipitated with $1 \mathrm{ml}$ absolute ethanol, and suitable samples of the ethanol extract were assayed. The interassay coefficient of variation was $\sim 16 \%$. Plasma samples were coded by number only and run in batches of 24 without any knowledge of time of collection or reproductive status of the animal. Attempts to assay oestrogen were unsuccessful since the amounts present were below the sensitivity limit $(10 \mathrm{pg})$ of our assay system.

\section{Results}

\section{Reproductive tract morphology}

Bats were placed in three categories based on reproductive tract morphology. (1) Nulliparous bats with small uteri lacked antral follicles, although variable numbers of small to medium-sized secondary follicles were present in both ovaries. Uterine horns were straight and tubular, averaging $0.65 \mathrm{~mm}$ in diameter. Average lengths for right and left horns were $2.1 \mathrm{~mm}$ and $1.7 \mathrm{~mm}$, respectively, although in $40 \%$ of specimens the two horns were symmetrical. (2) Nulliparous bats with swollen 
uteri did have a mature follicle. Uterine horns, while still tubular, were enlarged, slightly convex along the antimesometrial (cranial) border, and unequal; right horns averaged $2.4 \mathrm{~mm}$ long by $1.1 \mathrm{~mm}$ wide and left horns averaged $1.9 \mathrm{~mm}$ long by $1.0 \mathrm{~mm}$ wide. (3) Parous bats had a mature antral follicle and grossly asymmetric uteri. Right uterine horns were ampoule shaped due to the marked antimesometrial convexity, and averaged $2.5 \mathrm{~mm}$ long by $1.2 \mathrm{~mm}$ at the widest diameter. Left horns were conical, averaging $1.7 \mathrm{~mm}$ long by $1.1 \mathrm{~mm}$ at the confluence with corpus uteri. Because of their shape, left horns of parous bats are conspicuously smaller than left horns of nulliparous bats with swollen uteri.

Except for a subjective impression of enhanced vascularity in December, uterine appearance was unchanged during most of hibernation. However, some uteri examined in late February and March exhibited slight turgidity and variable degrees of hyperaemia. There was no histological evidence of uterine activity except in February and March when occasional mitotic figures were seen in the luminal and glandular epithelia of females of all three categories. Uterine glands, however, were not enlarged compared to earlier specimens. With few exceptions, spermatozoa were found in the uterus and/or oviducal isthmus of all bats examined. In all specimens, the vaginal epithelium was fully cornified.

The ovaries of parous bats and nulliparous bats with swollen uteri were similar and conformed to the classic descriptions of Guthrie \& Jeffers (1938) and Wimsatt (1944). Ovaries of some bats collected in December and February contained an above average number of small secondary follicles, but there was no discernible increase in mitotic activity to suggest that this was due to follicular growth. Glycogen was present in the cumulus oophorus cells of the mature follicle and in atretic follicles, several of which were found in all ovaries, but secondary follicles never stained positively for glycogen.

The ovaries of nulliparous bats with small uteri contained multilaminar follicles, indicating prior follicular activity, but the number of larger secondary follicles varied greatly among individual bats. In no instance was there any evidence of antrum formation, and glycogen was found only in atretic follicles. The number of nulliparous bats lacking mature follicles varied from one collection to another, but there was no change in the proportions of bats in each category between the first and second halves of hibernation (Table 1).

Table 1. Plasma progesterone concentrations $(\mathrm{ng} / \mathrm{ml})$ in hibernating little brown bats collected 1983-84

\begin{tabular}{|c|c|c|c|c|}
\hline \multirow[b]{2}{*}{$\begin{array}{l}\text { Collection } \\
\text { date }\end{array}$} & \multicolumn{2}{|c|}{ Nulliparous } & \multirow[b]{2}{*}{ Parous } & \multirow[b]{2}{*}{ Total ${ }^{*}$} \\
\hline & $\begin{array}{c}\text { Small } \\
\text { uteri }\end{array}$ & $\begin{array}{c}\text { Swollen } \\
\text { uteri }\end{array}$ & & \\
\hline 19-25 Sep. & $5 \cdot 1 \pm 0 \cdot 3(7)$ & $3.7 \pm 0.8(6)$ & $5.7 \pm 0.9(9)$ & $5 \cdot 0 \pm 0.5^{a}$ \\
\hline 12 Oct. & $6.7 \pm 0.8(4)$ & - & $6.4 \pm 0.9(4)$ & $6.6 \pm 0.6^{\mathrm{ab}}$ \\
\hline 17 Nov. & $2.9 \pm 0.2(3)$ & $2.3 \pm 0.7(2)$ & $3.0 \pm 1.2(5)$ & $2 \cdot 8 \pm 0.6^{\mathrm{a}}$ \\
\hline $12 \mathrm{Dec}$. & $25 \cdot 6$ & $25.9 \pm 7.6(5)$ & $26.4 \pm 13.6(3)$ & $26.1 \pm 6.4^{c}$ \\
\hline $17 \mathrm{Jan}$. & $4.3 \pm 0.4(6)$ & $5.0 \pm 0.4(7)$ & $3.7 \pm 0.5(7)$ & $4 \cdot 4 \pm 0.3^{\mathrm{a}}$ \\
\hline 16 Feb. & $13 \cdot 3$ & $12 \cdot 6 \pm 1 \cdot 6(5)$ & $11 \cdot 1 \pm 3 \cdot 2(7)$ & $11.8 \pm 1.8^{b}(13)$ \\
\hline 15 Mar. & $8.2 \pm 0.8(4)$ & $6.5 \pm 0.6(2)$ & $7.5 \pm 1.3(7)$ & $7 \cdot 5 \pm 0.7^{\mathrm{ab}}(13)$ \\
\hline 23-30 Mar. & $5 \cdot 9 \pm 1 \cdot 1(3)$ & $8.1 \pm 0.5(8)$ & $11.3 \pm 4.6(5)$ & $8 \cdot 7 \pm 1.5^{b} \quad(16)$ \\
\hline
\end{tabular}

Values are mean \pm s.e.m. for no. of bats shown in parentheses.

*One-way analysis of variance showed $\mathrm{F}_{(4.09)}=14.86$, d.f. $=7,102, P<0.001$.

a,b,c Figures without common superscripts differ statistically $(P<0.05)$ by Duncan's multiple range test.

\section{Plasma progesterone concentrations}

Concentrations varied markedly during hibernation (Table 1), but analyses of variance showed that, within a given collection period, there were no differences between bats of different reproductive 
categories. Therefore, all results for each period were combined for further analysis. Mean plasma progesterone values at the beginning of hibernation were $35 \%$ lower than mean concentrations of $7.7 \mathrm{ng} / \mathrm{ml}(\mathrm{N}=10)$ recorded from active bats collected at the mine entrance at the end of August. Seasonal low values $(2.8 \mathrm{ng} / \mathrm{ml})$ recorded in November were followed by a 10 -fold increase in December. January concentrations were again low, but February levels were 3-fold higher. Plasma progesterone values in March were intermediate between February values and concentrations of $5-6 \mathrm{ng} / \mathrm{ml}$ were recorded in anovulatory bats shortly after arousal in April. Coefficients of variation for the mean combined values ranged from 24 to $68 \%$, indicating a lack of homogeneity within samples, most of which was attributable to parous bats. Nevertheless, one-way analysis of variance showed significant interactions between monthly samples, and Duncan's multiple range test showed statistically significant differences between mean monthly values during the middle half of hibernation.

Table 2. Plasma progesterone concentrations $(\mathrm{ng} / \mathrm{ml})$ in little brown bats collected November 1984-February 1985

\begin{tabular}{lccc}
\hline & \multirow{2}{*}{$\begin{array}{c}\text { No. of } \\
\text { bats }\end{array}$} & Range & Mean \pm s.e.m. \\
\cline { 3 - 4 } & 4 & $3 \cdot 3-13 \cdot 4$ & $8 \cdot 1 \pm 2 \cdot 4$ \\
\hline 12 Nov. & 5 & $1 \cdot 8-6.5$ & $4 \cdot 9 \pm 0.8$ \\
15 Jan. & 4 & $6 \cdot 4-13 \cdot 8$ & $9 \cdot 7 \pm 1 \cdot 6$ \\
12-19 Feb. & 5 & $4.4-7.6$ & $6 \cdot 0 \pm 0.6$ \\
\hline
\end{tabular}

One-way analysis of variance showed $F_{(3 \cdot 34)}=2 \cdot 44$, d.f. $=3,14 P>0 \cdot 10$.

Table 2 lists plasma progesterone values obtained from female bats used as controls in another study conducted from November 1984 through February 1985. Although the sample sizes are small and the collection intervals are different, the handling and examination procedures were the same and values should have been comparable to those in Table 1. As shown, mean progesterone values for the four mid-monthly samples differed from the corresponding values in Table 1 . There was a suggestion of periodic variation in successive months, but the pattern of change was out of phase with respect to changes shown in Table 1 , and in any case the differences were not statistically significant.

\section{Discussion}

Our results show that hibernating little brown bats frequently display elevated plasma progesterone concentrations. In contrast, Oxberry (1979) found uniformly low ( $\sim 5 \mathrm{ng} / \mathrm{ml})$ progesterone values from August until March in hibernating pallid bats (Antrozous pallidus). While changes in plasma progesterone imply corresponding changes in ovarian activity, peripheral progesterone levels can also be increased by stress-induced changes in adrenal function (Vermeulen, 1976). The possibility of confounding effects due to stress can never be excluded entirely, especially when examining wild animals. In the present study, however, any such effects should have been equivalent from one collection period to another, since collection and handling methods were kept uniform throughout, and there was no evidence of environmental change or disturbance within the hibernaculum. It is unlikely, therefore, that the changes in progesterone concentrations which we observed are attributable to changes in adrenal progesterone production.

The recurrent changes in monthly plasma progesterone values (Table 1), which during the middle half of hibernation were statistically significant, show an apparent periodicity of about 60 

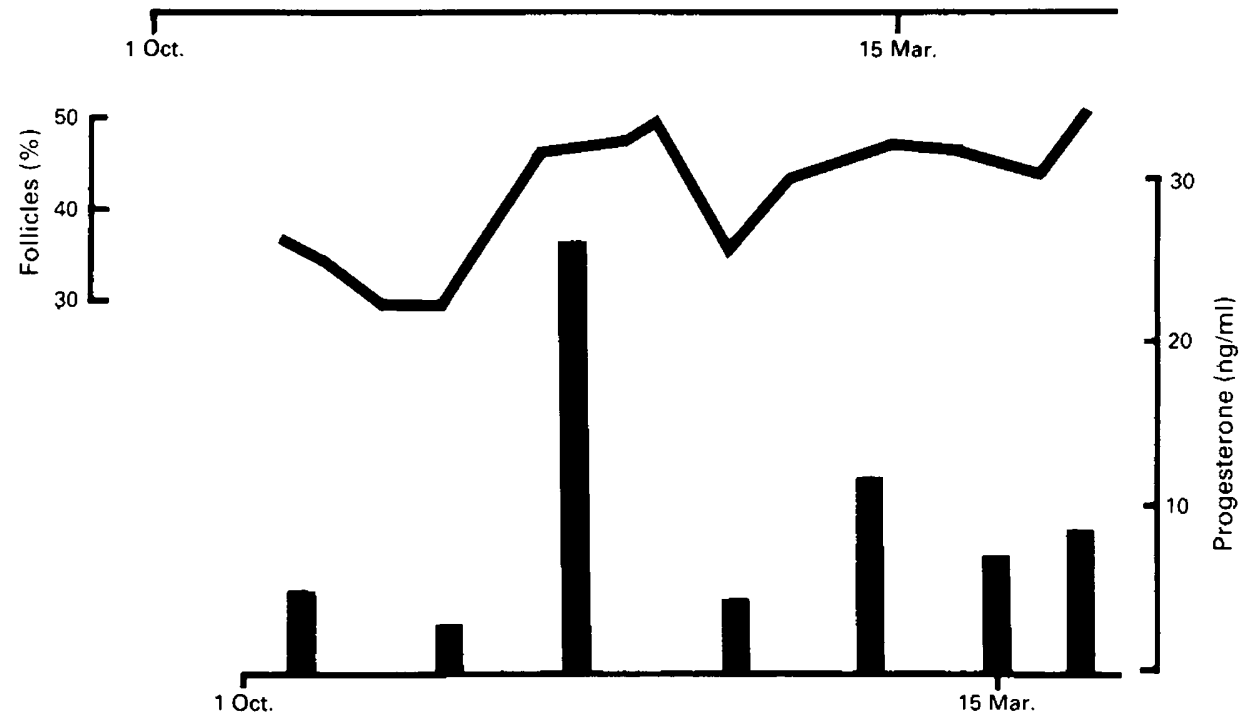

Fig. 1. Correlation between growth of small $(24-43 \mu \mathrm{m})$ follicles (Guthrie \& Jeffers, 1938) and plasma progesterone concentrations (this study) in hibernating little brown bats. The line indicates the number of small follicles as a percentage of total growing follicles. The vertical bars represent mean plasma progesterone in mid-monthly samples in Table 1 . As shown by the upper and lower time bars (on which 1 October and 15 March are indicated), the data have been offset by 3 weeks to compensate for the difference in times of entry into hibernation in the two studies.

days. Guthrie \& Jeffers (1938) found recurrent waves of secondary follicular growth, which also showed a periodicity of about 60 days, in the ovaries of hibernating little brown bats. A comparison of their data for small $(24-43 \mu \mathrm{m})$ follicles with our progesterone data (Fig. 1) reveals a striking correlation, and raises the possibility that the hypothalamus and pituitary may exhibit rhythmic activity during hibernation. Unfortunately, the data in Table 2 are incompatible with this interpretation, since they do not show any clear indication of episodic changes. The reasons for this disparity are not certain. However, activity levels in the hibernating colony were quite different in the two study seasons and it is reasonable to infer that variations in metabolic state (e.g. depth of hibernation, frequency and timing of arousal) had corresponding effects on ovarian activity which are reflected in the plasma progesterone.

During early hibernation, there is substantial activity (vocalization, flying, mating) within the hibernaculum, arousals are frequent, and many bats apparently continue to forage daily for some time after assuming residence (McNab, 1982). With transition to deep torpor, arousals become infrequent and activity declines to negligible levels until late hibernation when it again increases. In 1983, activity was conspicuous in September, but by early November the hibernating population had reached full size (4000-4500 bats) and the colony was in deep torpor. The mean progesterone concentrations in Table 1 do correlate with these changes in activity, i.e. values during early hibernation were not remarkably different from those in active bats at the end of the active season, and marked fluctuations were recorded only during the period of deep torpor. This latter observation seems paradoxical; however, the relatively rapid build-up of the hibernating population in 1983 would presumably impose greater synchrony on the timing of spontaneous periodic arousals and thereby increase the probability of detecting changes associated with arousal. In contrast, entry into hibernation in 1984 was protracted due to mild weather (colony size did not reach 4000 until January 1985) and considerable activity was observed on all visits before that time. As a result, the bats collected in 1984-85 were much more variable with respect to tenure within the hibernaculum 
and depth of hibernation than in the previous season, and this variability appears to be reflected in the progesterone data in Table 2, which indeed resemble progesterone values recorded during early hibernation in Table 1. Based on the present evidence, we suggest that it is reasonable to conclude that ovarian activity during hibernation is modulated by metabolic level, not by any inherent rhythmicity.

Several studies have concluded that most female little brown bats mature sexually before their first hibernation (Guthrie, 1933; Smith, 1954; Wimsatt \& Kallen, 1957; O'Farrell \& Studier, 1975; Humphrey \& Cope, 1976). However, the age at which vespertilionid bats attain sexual maturity can vary within species due to environmental conditions (Racey, 1974). Indeed, Schowalter et al. (1979) found a number of nulliparous females in summer (non-maternity) roosts in central Alberta, Canada $\left(52-55^{\circ} \mathrm{N}\right)$ and concluded that, at that latitude, female little brown bats did not mature until they were yearlings. The lack of any evidence in the present study that nulliparous females with small uteri form antral follicles during hibernation, and other studies (Buchanan \& YoungLai, 1986; Buchanan, 1987) indicating that this does not occur at the end of hibernation, suggests that these bats are sexually immature; however, the presence of fully cornified vaginae in all and intrauterine spermatozoa in nearly all would, by Racey's (1974) criteria, label them as sexually mature. In addition, bats with small uteri displayed changes in progesterone concentrations during hibernation which were indistinguishable from those seen in patently mature nulliparous and parous bats. These results, both morphological and physiological, suggest that the hypothalamus and pituitary of bats with small uteri were functioning in an adult (i.e. post-pubertal) manner and that reproductive competence was not achieved because of insufficient time to complete folliculogenesis before hibernation.

We thank Francesca C. Bullock for expert technical assistance in the laboratory, and Maria Buko-Buchanan for help in collecting bats from the hibernaculum. This work was supported by grants from the Medical Research Council of Canada.

\section{References}

Buchanan, G.D. (1987) Timing of ovulation and early embryonic development in Myotis lucifugus (Chiroptera: Vespertilionidae) from northern central Ontario. Am. J. Anat. 178, 335-340.

Buchanan, G.D. \& YoungLai, E.V. (1986) Plasma progesterone levels during pregnancy in the little brown bat, Myotis lucifugus (Vespertilionidae). Biol. Reprod. 34, 878-884.

Guraya, S.S. \& Greenwald, G.S. (1964) A comparative histochemical study of interstitial tissue and follicular atresia in the mammalian ovary. Anat. Rec. 149, 411-433.

Guthrie, M.J. (1933) The reproductive cycles of some cave bats. J. Mammal. 14, 199-216.

Guthrie, M.J. \& Jeffers, K.R. (1938) Growth of follicles in the ovaries of the bat Myotis lucifugus lucifugus. Anat. Rec. 71, 477-496.

Humphrey, S.R. \& Cope, J.B. (1976) Population ecology of the little brown bat, Myotis lucifugus, in Indiana and north-central Kentucky. Special Publication No. 4. American Society of Mammalogists, $81 \mathrm{pp}$.

Lillie, R.D. (1965) Histopathologic Technic and Practical Histochemistry, 3rd edn. McGraw-Hill, New York.

McNab, B.K. (1982) Evolutionary alternatives in the physiological ecology of bats. In Ecology of Bats, pp. 151-200. Ed. T. H. Kunz. Plenum Press, New York.
Morse, A. (1945) Formic acid-sodium citrate decalcification and butyl alcohol dehydration of teeth and bones for sectioning in paraffin. J. Dental Res. 24, $143-153$.

O'Farrell, M.J. \& Studier, E.H. (1975) Population structure and emergency activity patterns in Myotis thysanodes and $M$. lucifugus (Chiroptera: Vespertilionidae) in northeastern New Mexico. Am. Midland Naturalist 93, 368-376.

Oxberry, B.A. (1979) Female reproductive patterns in hibernating bats. J. Reprod. Fert. 56, 359-367.

Pearse, A.G.E. (1968) Histochemistry, Theoretical and Applied, 3rd edn. Churchill, London.

Racey, P.A. (1974) Aging and assessment of reproductive status of pipistrelle bats, Pipistrellus pipistrellus. $J$. Zool., Lond. 173, 264-271.

Racey, P.A. (1982) Ecology of bat reproduction. In Ecology of Bats, pp. 57-104. Ed. T. H. Kunz. Plenum Press, New York.

Racey, P.A., Uchida, T.A., Mori, T., Avery, M.A. \& Fenton, M.B. (1987) Sperm-epithelium relationships in relation to the time of insemination in little brown bats (Myotis lucifugus). J. Reprod. Fert. 80, 445-454.

Rossman, I. (1940) Deciduomal reaction in the rhesus monkey (Macaca mulatta): epithelial proliferation. Am. J. Anat. 66, 277-365. 
Schowalter, D.B., Gunson, J.R. \& Harder, L.D. (1979) Life history characteristics of little brown bats (Myotis lucifugus) in Alberta. Canadian FieldNaturalist 93, 243-251.

Serra, J.A. \& Queiroz Lopes, A. (1945) Une méthode pour la démonstration histochemique du phosphore des acides nucléiques. Portugaliae Acta Biol., Ser. A 1, 111-122.

Smith, E.W. (1954) Studies of the life history of noncave-dwelling bats in northwestern Ohio. Ohio J. Sci. 54, 1-12.

Vermeulen, A. (1976) Postmenopausal ovarian function. In The Endocrine Function of the Human Ovary, pp. 237-244. Eds V. H. T. James, M. Serio \& G. Guisti. Academic Press, London.
Wimsatt, W.A. (1944) Growth of the ovarian follicle and ovulation in Myotis lucifugus lucifugus. Am. J. Anat. 74, 129-173.

Wimsatt, W.A. (1960) Some problems of reproduction in relation to hibernation in bats. Bull. Mus. comp. Zool. Harv. 124, 249269.

Wimsatt, W.A. (1969) Some interrelationships of reproduction and hibernation in mammals. Symp. Soc. exp. Biol. 23, 511-549.

Wimsatt, W.A. \& Kallen, F.C. (1957) The unique maturation response of the Graafian follicles of hibernating vespertilionid bats and the question of its significance. Anat. Rec. 129, 115-131.

Received 20 May 1987 